\title{
Escola Nossa Senhora Aparecida: um movimento histórico de luta por escola*
}

\begin{abstract}
Resumo
O referido artigo trata da história da Escola de Educação Infantil e Ensino Fundamental Nossa Senhora Aparecida, localizada no município de Passos Maia/SC. A escola tem em sua gênese a vinculação com o Movimento dos Trabalhadores Rurais Sem Terra MST. A questão central deste estudo é a omnilateralidade da educação no contexto da luta por escola considerando a educação no MST. Seus objetivos fundamentais são: compreender os elementos que compõe a formação omnilateral em Marx; delinear as principais linhas políticas e os princípios filosóficos e pedagógicos básicos da educação no MST; analisar o movimento da trajetória histórica da escola atentando para os avanços obtidos, bem como os retrocessos tendo como base as linhas políticas; e os princípios da educação no MST bem como a educação omnilateral.
\end{abstract}

Palavras-chave: Educação omnilateral. Movimento Sem Terra. Formação humana.
Vagner Luiz Kominkiéwicz

Especialista em Ciências Humanas e Sociais para escolas do campo pela

Universidade Federal de Santa Catarina (UFSC). vagnerluka@gmail.com

\section{Jéferson Silveira Dantas}

Doutor em Educação. Professor no Departamento de Estudos Especializados em Educação (EED/CED/UFSC). clioinsone@gmail.com

\section{Para citar este artigo:}

KOMINKIÉWICZ, Vagner Luiz; DANTAS, Jéferson Silveira. Escola Nossa Senhora Aparecida: um movimento histórico de luta por escola. Revista PerCursos. Florianópolis, v. 14, n.26, jan./jun. 2013. p. $187-213$.

\section{DOI: $10.5965 / 1984724214262013187$}

http://dx.doi.org/10.5965/1984724614262013187

\footnotetext{
* Para a realização deste artigo contamos com a valiosa leitura da educadora Justina Inês Sponchiado Mestre em Educação pela PUC/SP e Doutora em Educação pela UFSC -, que além de contribuir com as questões formais do texto (grafia, normas da ABNT, estrutura semântica das orações, etc.), ainda fez significativas sugestões em seu conteúdo, objetivando uma síntese mais fluida e objetiva, sem ferir os princípios teóricos e metodológicos defendidos pelos autores.
} 


\title{
School Nossa Senhora
} Aparecida: a historical movement of struggle for school

\begin{abstract}
The article deals with the history of the Preschool and Elementary School Nossa Senhora Aparecida, in the city of Passos Maia/SC. The school has its genesis in linking with the Movimento dos Trabalhadores Rurais Sem Terra MST. The central question of this study is to omnilateral education in the context of the struggle for considering school education in the MST. Its main objectives are: to understand the elements that make up the training omnilateral in Marx; outline the main policy lines and philosophical principles and teaching of basic education in the MST; analyze the movement of the historical trajectory of the school paying attention to the progress made and setbacks based on the policy guidelines, and the principles of education in the MST as well as educationomnilateral.
\end{abstract}

Keywords: Education omnilateral. Movimento Sem Terra. Human formation. 


\section{Introdução}

O presente estudo tem como eixo central a análise do processo educacional da Escola de Educação Infantil e Ensino Fundamental Nossa Senhora Aparecida, do Assentamento Zumbi dos Palmares, município de Passos Maia/SC. Tem como base um estudo sobre a educação omnilateral ${ }^{1}$ em Marx e as linhas políticas e princípios da educação no Movimento dos Trabalhadores Rurais Sem Terra - MST. A partir desta delimitação, buscamos pontuar algumas questões que consideramos centrais para o estudo, cujo desenvolvimento se estruturou nos seguintes objetivos: a) compreender os elementos que compõem a formação omnilateral em Marx; b) delinear as principais linhas políticas e os princípios filosóficos e pedagógicos básicos da educação no MST; c) analisar o movimento da trajetória histórica da escola atentando para os avanços obtidos, bem como os retrocessos tendo como base as linhas políticas, os princípios da educação no MST, bem como a educação omnilateral. d) identificar algumas lições históricas que podemos absorver desta experiência de educação protagonizada pelo movimento social. A hipótese que orienta este estudo pretende demonstrar que a educação construída com base nos princípios e linhas políticas do MST possibilita a onilateralidade em contextos educativos reais. Ou seja, a prática desenvolvida como experiência em um contexto de luta e enfrentamento como o caso da escola em questão possibilita avançar para a formação completa do ser humano, considerando suas várias dimensões; que esta teoria

\footnotetext{
${ }^{1} \mathrm{O}$ conceito de omnilateralidade gira em torno do problema da educação em Marx. Ele se refere a uma formação humana oposta à formação unilateral provocada pelo trabalho alienado, pela divisão social do trabalho, pela reificação, pelas relações burguesas estranhadas. Esse conceito não foi precisamente definido por Marx, todavia, em sua obra há suficientes indicações para que seja compreendido como uma ruptura ampla e radical com o homem limitado da sociedade capitalista. $O$ autor a ela se refere sempre como a ruptura com o homem limitado da sociedade capitalista. Essa ruptura deve ser ampla e radical, isto é, deve atingir uma gama muito variada de aspectos da formação do ser social, portanto, com expressões nos campos da moral, da ética, do fazer prático, da criação intelectual, artística, da afetividade, da sensibilidade, da emoção, etc. Essa ruptura não implica, todavia, a compreensão de uma formação de indivíduos geniais, mas, antes, de homens que se afirmam historicamente, que se reconhecem mutuamente em sua liberdade e submetem as relações sociais a um controle coletivo, que superam a separação entre trabalho manual e intelectual e, especialmente, superam a mesquinhez, o individualismo e os preconceitos da vida social burguesa. "La propiedadad privada nos há vuelto tan estúpidos y unilaterales, que un objeto solo es nuestro cuando lo tenemos y, por tanto, cuando existe para nosotros como capital o cunado lo poseemos directamente, cuando lo comemos, lo bebemos, lo vestimos, habitamos en él, etc., en una palabra, cuando lo usamos." (MARX; ENGELS, 1987, p. 620). Escolhemos este conceito por identificar nele a essência em que se formularam as linhas políticas e os princípios de educação no MST.
} 
se sustenta em contextos reais, tendo por base o modo de produção capitalista e a formação unilateral do ser humano.

Para a realização desta análise, utilizamos três procedimentos metodológicos. Um deles foi a pesquisa de campo. Nesta utilizamos a observação da escola e a entrevista com educadores desta história, os quais vivenciaram todo o processo. Optamos pela Escola Nossa Senhora Aparecida por ser uma escola construída tendo como protagonistas trabalhadores do campo organizados pelo MST. A pesquisa de campo foi feita em dois momentos; inicialmente observando as atividades desenvolvidas na escola, sua estrutura organizativa; e num segundo momento dedicada à entrevista com as educadoras.

Para tornar possível a composição de nossa análise, buscamos diversos referenciais teóricos de apoio aos nossos estudos sobre a educação omnilateral, bem como sobre os princípios e linhas políticas da educação no Movimento dos Trabalhadores Rurais Sem Terra - MST. Por fim, o terceiro referencial diz respeito às fontes documentais da escola, tais como livros de atas e o Projeto Político e Pedagógico.

\section{O Homem Omnilateral}

A formação humana no atual modo de produção econômico e político tende a uma única dimensão: separam no ser as suas dimensões, considerando apenas aquela que interesse às necessidades do avanço econômico e/ou político do capital. O ser vai sendo "alienado" de uma formação que considere as diversas esferas da vida humana através do trabalho ou das relações de trabalho. Este princípio nos remete à reflexão sobre uma educação que saia do campo limitado da formação humana e vise ampliar, potencializar as suas várias dimensões.

Como foi dito acima, encontramos em Marx e Engels uma formulação sobre o desenvolvimento das várias dimensões humanas: a omnilateralidade. Tais autores viram o trabalho como fundamental para a existência humana. No seu ensaio inacabado O papel desempenhado pelo trabalho na transformação do macaco em homem, Engels diz que o trabalho "é a primeira condição básica para toda a existência humana, e isto numa tal 
extensão que, em determinado sentido, nós temos de dizer que o trabalho criou o próprio homem" (ENGELS, 2011, p. 1).

Diferentemente de Hegel, Marx não vê o trabalho apenas pelo seu aspecto positivo. Escreve nos Manuscritos de 1844 que "Hegel se coloca no ponto de vista dos modernos economistas nacionais. Ele apreende o trabalho como a essência, como a essência do homem que se confirma; ele vê somente o lado positivo do trabalho, não seu [lado] negativo". (MARX, 2004, p. 124). Sendo a essência subjetiva da propriedade privada no capitalismo, aparece ao trabalhador como propriedade de outro, alheia a ele. Marx problematiza a relação do trabalhador com o resultado de seu trabalho, o produto final.

Mas o estranhamento não se mostra somente no resultado, mas também, e principalmente, no ato da produção, dentro da própria atividade produtiva. Como poderia o trabalhador defrontar-se alheio (fremd) ao produto da sua atividade se no ato mesmo da produção ele não se estranhasse a si mesmo? O produto é, sim, somente o resumo (Resumé) da atividade, da produção. (MARX, 2004, p.82)

A alienação do trabalhador não se dá unicamente na relação com o objeto, produto do trabalho, mas no ato de produzir há estranhamento. Se o produto do trabalho humano é a exteriorização, o processo de produção do produto é a exteriorização da atividade humana. Assim, Marx conclui que a exteriorização está na atividade do trabalho. Se o ser humano não se reconhece no produto do seu trabalho, fica posto um estranhamento. E, na produção, o trabalho é exterior ao processo de produzir.

Em que consiste, então, a exteriorização (Entäusserung) do trabalho? Primeiro, que o trabalho é externo (Äusserlich) ao trabalhador, isto é, não pertence ao seu ser, que ele não se afirma, portanto, em seu trabalho, mas nega-se nele, que não se sabe bem, mas infeliz, que não desenvolve nenhuma energia física e espiritual livre, mas mortifica sua physis e arruína o seu espírito. O trabalhador só se sente, por conseguinte e em primeiro lugar, junto a si [quando] fora do trabalho e fora de si [quando] no trabalho. Está em casa quando não trabalha e, quando trabalha, não está em casa. O seu trabalho não é, portanto, voluntário, mas forçado, trabalho obrigatório. [...] Finalmente, a externalidade (Äusserlichkeit) do trabalho aparece para o trabalhador como se [o trabalho] não fosse seu próprio, mas de um outro, como se [o trabalho] não lhe pertencesse, como se ele no trabalho não pertencesse a si mesmo, mas a um outro. Assim, como religião e auto-atividade de fantasia humana, do cérebro e 
do coração humanos, atua independentemente do indivíduo e sobre ele, isto é, como atividade estranha, divina ou diabólica, assim também a atividade do trabalhador não é a sua auto-atividade. Ela pertence a outro, é a perda de si mesmo (MARX, 2004, p.82-83).

Podemos considerar dois elementos até o momento: 1) a alienação humana tem origem na divisão social do trabalho e 2) a partir desta divisão social do trabalho o ser humano passa a ser incompleto e unilateral.

Retomemos, pois, os níveis em que se expressa a alienação humana a partir das relações sociais determinantes, que tem por base a propriedade privada de produção e a divisão social do trabalho. Quando o ser humano passa a viver o trabalho alienado, ele se aliena da relação com a natureza, tendo em vista que é através do trabalho que o ser humano com ela se relaciona, humanizando-a e podendo assim compreendê-la. Vivendo relações estranhadas de trabalho o próprio ser humano se "coisifica" e o produto de seu trabalho lhe é estranho; ocorre aqui um distanciamento na relação com a natureza.

Outro aspecto diz respeito à alienação de homens e mulheres em sua atividade. $\mathrm{O}$ trabalho deixa de ser ação própria da vida e vira um meio para sobreviver. O trabalho é exterior, para outrem. O prazer, o gozo/gosto pelo trabalho se esvai, torna-se trabalho forçado, gera aflição e sofrimento. O ser humano é alienado de si mesmo, pois é alienado daquilo que o humaniza: o trabalho.

E, por fim, sendo alienado de si como ser humano ele se coisifica ${ }^{2}$, vende seu trabalho, aquilo que o torna ser humano e que o define como espécie. Este se torna “indivíduo" separado da espécie humana. O trabalho deixa de ser o elo entre o "homem" e sua espécie e se transforma em um meio individual de sobrevivência.

Sistematizando a alienação, podemos descrevê-la em três aspectos:

a) O ser humano alienado da natureza;

b) O ser humano alienado de si;

c) O ser humano alienado de sua espécie.

\footnotetext{
$2 \mathrm{O}$ animal não se encontra em relação com coisa alguma, não conhece de facto qualquer relação; para o animal, as relações com os outros não existem enquanto relações. A consciência é, pois, um produto social e continuará a sê-lo enquanto houver homens. (MARX; ENGELS, 1980, p.35-36).
} 
O trabalho para Marx e Engels é parte da história humana, mais que isto, é "gênese" humana em si, sendo que é a partir do trabalho que o ser humano se desenvolveu humano. Sendo o trabalho característica vital do ser humano, ele, no sistema capitalista, carrega a contradição de ser o seu contrário, de se transformar em nocividade. É a partir da divisão social do trabalho que elementos de um ser unilateral vêm à tona, ao desenvolver parte da ação necessária à sua sobrevivência e desenvolverse fragmentadamente como algo estranho a si e na relação com os outros.

A partir do momento em que o ser humano é "alienado" materialmente na produção da vida, em que os meios de produção passam a ser de propriedade privada alheia ao trabalhador, e que este é submetido à divisão social do trabalho, alienado de si e de seu trabalho, estranhado às relações sociais de produção e do fruto de seu trabalho, e de sua espécie, identifica-se também outro aspecto que culmina paralelamente à alienação material, que desenvolveremos a seguir. No prefácio de "Para a Crítica da Economia Política", Marx demonstra sucintamente o funcionamento das relações sociais capitalistas, a estrutura econômica sob a qual se ergue toda a superestrutura política e jurídica que correspondem a determinadas formas de consciência social.

O resultado geral que se me ofereceu e, uma vez ganho, serviu de fio condutor aos meus estudos, pode ser formulado assim sucintamente: na produção social da sua vida os homens entram em determinadas relações, necessárias, independentes da sua vontade, relações de produção que correspondem a uma determinada etapa de desenvolvimento das suas forças produtivas materiais. A totalidade destas relações de produção forma a estrutura econômica da sociedade, a base real sobre a qual se ergue uma superestrutura jurídica e política, e à qual correspondem determinadas formas da consciência social. $O$ modo de produção da vida material é que condiciona o processo da vida social, política e espiritual. Não é a consciência dos homens que determina o seu ser, mas, inversamente, o seu ser social que determina a sua consciência (MARX, 2011, p. 1)

As determinações do ser humano no campo da consciência social se definem com base na forma em que produz a vida. Moral, religião, política são determinações do ser social nas relações sociais de base material para a produção da vida. Ou seja, a propriedade privada e a divisão social de trabalho, com o trabalho 
assalariado, determinam uma forma ${ }^{3}$ específica de consciência social. A alienação do trabalhador apresentada nos níveis descritos acima - alienados da natureza, de si e de sua espécie - são previamente determinados ao campo da consciência social.

Embora possamos pensar que o ser humano tem em si todas as condições objetivas ou subjetivas para agir na plenitude de sua consciência, ou mesmo de suas vontades manifestas por acreditar ser este seu caráter universal da atividade humana, oposto ao domínio da casualidade, vemos que isto não procede de maneira lógica e irrefutável. A capacidade da ação consciente humana é também alienada, pois está na esfera "superior" das relações sociais de produção. Este que em outra situação de relação social ${ }^{4}$ domina as relações necessárias ao seu desenvolvimento material e espiritual, aqui se encontra subsumido ${ }^{5}$ às relações capitalistas de produção, assentadas na propriedade privada dos meios de produção. Chegamos aqui ao indivíduo parcial, desprovido da totalidade. Um ser metamorfoseado historicamente pelas relações de produção, um ser unilateral.

Este ser é sujeito às transformações impulsionadas pelo movimento histórico do modo de produção ${ }^{6}$, capaz de superar a unilateralidade. Porém não sozinho, ou por força de sua vontade, e sim por determinações do próprio movimento em si. No momento em que o ser humano passe a se apropriar da totalidade dos instrumentos de produção é que se pode chegar à sua completude, à transformação dos indivíduos unilaterais em indivíduos completos em suas várias dimensões.

[...] ao passo que na sociedade comunista, na qual cada homem não tem um círculo exclusivo de atividade, mas se pode adestrar em todos os ramos que preferir, a sociedade regula a produção geral e, precisamente desse modo, torna possível que eu faça hoje uma coisa e amanhã outra, que cace de manhã, pesque de tarde, crie gado à tardinha, critique

\footnotetext{
${ }^{3}$ Considerando que a alienação do homem nos três níveis trabalhados neste artigo (da natureza, de si e de sua espécie) está na base material da sociedade, na estrutura econômica, reflete neste (o ser humano) uma forma de consciência igualmente alienada.

${ }^{4}$ Aqui chamamos a atenção para as relações sociais de produção da vida assentadas no comunismo primitivo, caracterizado principalmente pela propriedade coletiva dos meios de produção.

${ }^{5}$ Conceito desenvolvido por Marx para revelar, dentro do processo de produção, a subsunção do trabalho para o capital na produção da mais-valia.

${ }^{6}$ Falamos aqui em específico do modo de produção capitalista, considerando seu movimento carregado de contradições e carregado de embriões que possibilitam as rupturas.
} 
depois da ceia, tal como me aprouver, sem ter de me tornar caçador, pescador, pastor ou crítico (MARX, ENGELS, 2002. p. 39).

Ainda que, desafiadoramente, em formas outras de trabalho advindas após a revolução industrial, o trabalho é a base pela qual emergem as possibilidades do "homem" omnilateral - mas por meio do fim da divisão do trabalho, da exploração do trabalho e da sociedade de classes.

\section{A Educação Omnilateral}

A omnilateralidade pode ser compreendida em Marx como uma ruptura ampla e radical com o ser humano limitado da sociedade capitalista. Essa ruptura não implica, todavia, a compreensão de uma formação de indivíduos geniais, mas antes de homens e mulheres que se afirmam historicamente, que se reconhecem mutuamente em sua liberdade e submetem as relações sociais a um controle coletivo, que superam a separação entre trabalho manual e intelectual; e, especialmente, superam a mesquinhez, o individualismo e os preconceitos da vida social burguesa.

A humanidade aprende através dos órgãos sensoriais, com os quais sente, vê, ouve, fala. Esta captação feita pelo ser humano através dos sentidos refere-se à captação do mundo concreto, material, ao qual está inserido. A humanidade aprende pela atividade social, pelo trabalho. É pela sua ação no meio através do trabalho que o ser humano se forma e transforma o meio social material. Este caráter "humanizante" do trabalho se desfaz sob o modo de produção capitalista, pois a espécie humana resume-se à força de trabalho disponível a ser vendida (como não proprietário dos meios de produção) aos proprietários dos meios. A vida torna-se apenas um meio, que tem como fim a alienação do trabalhador. A base deste processo é a propriedade privada dos meios de produção. Neste sentido, a educação aparece como elemento de sustentação ideológica de dominação e perpetuação das atuais relações sociais de produção, reflexo da base material de relações de trabalho. Ela, a educação, é fruto das relações de trabalho da base material de produção bem como meio de perpetuação das relações hegemônicas. Se a educação é resultado e não produto, como pode ela contribuir para a formação de 
homens e mulheres omnilaterais? A educação, sendo elemento de manutenção da hierarquia social, não pode, por si só, ser um instrumento de transformação, revolução das relações de produção. Sob a ótica da alienação humana através do trabalho no capitalismo, a educação está para reforçar ou mesmo naturalizar as relações de dominação.

Já vimos que o desenvolvimento da omnilateralidade em sua totalidade só é possível ao se revolucionarem as relações de produção, através da extinção da propriedade privada, da divisão do trabalho, da reificação e, por conseguinte, da alienação.

Somente quando a prática produtiva material e a prática social revolucionária alcançam certo nível na própria realidade é que se dão as condições para que se possa captar a prática, em toda a sua significação social e humana, em toda a sua universalidade, riqueza e essencialidade, como atividade transformadora do mundo (VÁZQUEZ, 1996, p. 157).

Com base na crítica à divisão social do trabalho, a qual afeta as mentes e os corpos dos trabalhadores, Marx (1989) propõe a união entre a escola e o trabalho, tendo como ponto de partida o “concreto real”. Não cabe à educação a tarefa de transformar, revolucionar o mundo, elevar o ser humano à formação omnilateral; no entanto a educação na relação com o trabalho faz emergir possibilidades, mesmo que em gérmens de uma formação omnilateral. O homem pode, através desta relação educação/trabalho, ir se apropriando das técnicas e das ciências, uma unidade entre a práxis e a teoria. Elementos de ruptura para com as unilateralidades burguesas são exercitados cotidianamente por meio de relações diferenciadas com a natureza, com a propriedade, com o outro, com as crianças, com as artes, com o saber, por intermédio de relações sociais de novo tipo.

Note-se ainda que o trabalho físico alheio da atividade intelectual destrói a natureza humana, bem como a atividade intelectual à margem do trabalho físico conduz facilmente a um idealismo artificial e de falsa abstração. O caráter integral da educação se dá na relação entre estes dois elementos, não dissociados nem tampouco isolados, mas em conformidade de relação dialética dentro do movimento histórico em questão. 


\section{Linhas Políticas da Educação no MST}

A educação no MST nasceu de uma trajetória de lutas de trabalhadores rurais organizados na luta pela terra conquistando um espaço dentro de uma sociedade de excluídos. Logo de início as famílias organizadas perceberam que a luta pela terra exigia mais do que a própria terra. Mesmo antes da conquista da terra, surgiram outras necessidades, como a de escola para as crianças que estavam nos acampamentos. Ter escola dentro do acampamento já era uma conquista, embora insuficiente. Percebeu-se a necessidade de lutar não apenas por escola, mas por uma educação voltada à realidade dos trabalhadores.

Com o tempo, vários acampamentos foram surgindo, vários hectares de terras foram sendo conquistados através do esforço e sacrifício das famílias que, por vezes, pagaram com a própria vida para exercer o direito à terra e à dignidade. A população de trabalhadores sem terra foi aumentando, e foi aumentando também o número de crianças desprovidas do direito à educação. Com isso, novas demandas foram postas para a organização dos trabalhadores, principalmente a de definir que tipo de educação precisaria ser construído.

Durante $06^{\circ}$ Encontro Nacional do $\mathrm{MST}^{7}$, foi construído coletivamente $\mathrm{o}$ documento Educação no Documento Básico do $\mathrm{MST}^{8}$. As linhas políticas da educação no MST foram criadas a partir das necessidades reais produzidas pela luta dos trabalhadores rurais, com o objetivo de orientar a forma e o caminho (método) a seguir:

Entre as linhas políticas estão:

- Transformar as escolas em instrumentos de transformação social e de formação de militantes do MST e de outros movimentos sociais com o mesmo projeto político.

- Desenvolver uma proposta de educação que proporcione às crianças, conhecimento e experiências concretas de transformação da realidade, a partir dos desafios do assentamento ou acampamento, preparando-se crítica e criativamente para participar dos processos de mudança da sociedade.

\footnotetext{
${ }^{7}$ Este encontro foi realizado em Piracicaba, estado de São Paulo, em fevereiro de 1991.

${ }^{8}$ ITERRA - Instituto Técnico de Capacitação e pesquisa da Reforma Agrária, MST - Setor de Educação. $1^{\text {a }}$ Ed. - Agosto de 2005.
} 
- A prática de educação nas escolas de assentamento/acampamento deve seguir os seguintes princípios:

a) ter trabalho e a organização coletiva como valores educativos fundamentais;

b) integrar a escola na organização do assentamento;

c) formação integral e sadia da personalidade da criança;

d) a prática da democracia como parte essencial do processo educativo;

e) o professor deve ser sujeito integrado na organização e interesses do assentamento;

f) a escola e a educação devem construir um projeto alternativo de vida social;

g) uma metodologia baseada na concepção dialética do conhecimento;

h) Produzir coletivamente a base de conhecimentos científicos mínimos necessários para o avanço da produção e da organização dos assentamentos.

i) Ampliar e fortalecer a relação entre escola e o assentamento. E entre a escola e o MST. (Dossiê MST Escola, 2005, p.29).

Garantir, na prática, estas linhas políticas demandaria muita organização interna e o "enfrentamento" com o Estado; e, no entanto, elas valem todo o esforço empreendido, pois elevam a escola e a educação a outro patamar: a educação assume um caráter de classe, fundada pela e para a classe trabalhadora, visando à transformação social. No nosso entendimento, a educação não pode conformar a realidade social na qual estamos inseridos; seu papel é transformá-la, conhecendo e realizando "experiências concretas" de efetiva transformação. A base para esta preparação são os desafios existentes nos acampamentos e assentamentos, intervindo diretamente nesta realidade, tanto para conhecê-la em um movimento de aparência para a essência, quanto para interferir neste meio. Todos os processos que envolvem esta política de educação devem visar à formação crítica dos estudantes a ponto de estes se engajarem nos processos de “mudança da sociedade".

As linhas políticas da educação no MST apontam para a vinculação da escola e da educação à realidade do assentamento e acampamento. Os vínculos com a organização e o trabalho do meio social são considerados para que a escola seja parte da vida do assentamento. A reciprocidade de ações entre escola e acampamento/assentamento pode permitir uma interação de ações vinculadas às necessidades reais que ambos 
apresentam. Para o MST, é papel da escola contribuir com um "projeto alternativo de vida social" para a comunidade, e a comunidade pode contribuir com a construção da educação na escola.

As linhas políticas da educação no MST visam também orientar para a produção de um conhecimento científico que possibilite o avanço para técnicas produtivas e a organização dos assentamentos e/ou acampamentos, ou seja, produzir conhecimento calcado na realidade social e organizativa, que contribua para melhorar a vida das pessoas que ali vivem. Não lhe interessa o conhecimento abstrato, desvinculado de um cunho social, uma vez que, para o movimento, produzir conhecimento significa produzir vida.

Os princípios da educação no MST foram elaborados pelo Coletivo Nacional do Setor de Educação, publicados em 1992, e em 1996 o documento foi reescrito com a finalidade de revisar e atualizar o texto original. Tal análise teve a preocupação de manter os elementos dos princípios originais, considerando-os juntamente com a atualização feita em 1996. Manteremos a lógica histórica de construção dos princípios no desenrolar da análise que segue.

Partimos do pressuposto de movimento histórico de construção, carregado de contradições, de idas e vindas em busca de objetivos bem delineados:

A organização de que fazemos parte está cada vez maior e mais complexa. A luta dos trabalhadores cresce em necessidade e força. Por isso, os desafios também aumentam e ficam mais complexos. A educação precisa assumir as tarefas que lhe cabem neste processo de fortalecimento da nossa organicidade, de clareza do projeto político dos trabalhadores e de construção prática e cotidiana da sociedade da justiça social e da dignidade humana, em nosso país, em nosso continente, no mundo todo (ITERRA, 2005. p. 159).

A citação acima indica quais são os princípios de que tratamos, qual seu cunho político e a que fins foram elaborados. Ao tratar de princípios, a referência não é apenas à ideia de começo, embora isso não possa ser descartado. Eles são carregados de intencionalidade política, e frutos de uma trajetória construída no processo de fazer educação, de fazer escola. São "algumas ideias/convicções/formulações que são as balizas (estacas, marcos, referências) para nosso trabalho de educação no MST" (ITERRA, 
2005. p. 160). Partindo de uma experiência em desenvolvimento é que se fez necessária a

elaboração e sistematização de marcos que revelassem a intencionalidade da experiência e servissem de arrimo à continuação do processo.

Os princípios aqui trabalhados possuem duas dimensões. Uma dimensão se refere à questão filosófica, tratando de uma visão de mundo que têm em interação seres humanos e a sociedade, e ao entendimento do que é a educação. Outra dimensão, dos princípios pedagógicos, está mais direcionada à forma de se pensar e fazer a educação, em vista de concretizar os próprios princípios filosóficos. Em suma, nos princípios temos a questão dos objetivos mais estratégicos do trabalho educativo no MST e uma reflexão acerca da metodologia a ser trabalhada.

\section{Princípios Filosóficos}

A filosofia de educação no MST tem caráter político e vislumbra a transformação de um atual estado social. É um processo pedagógico que se assume como político ao se revestir de valores humanistas e socialistas, tendo como base a radicalidade democrática em sua concepção de sociedade. Essa radicalidade parte da negação do atual estado de coisas, ou seja, da introdução de uma nova filosofia e novas práticas que negam e ferem a conformidade com a realidade vigente e vislumbram práticas transformadoras para uma nova sociedade.

A educação de classe é, portanto, uma das características expostas nos documentos do MST para a educação. Parte do pressuposto de que há duas classes na sociedade, em constante disputa hegemônica. Esta educação tem posição politicamente definida e clara: é uma educação de classe, da classe trabalhadora; tem por fim avançar nos níveis de consciência da classe bem como para uma consciência revolucionária; assume, então, uma posição política de não neutralidade, posicionada para e com a sua classe, a dos trabalhadores.

A educação vinculada ao movimento social de forma orgânica possibilita participar efetivamente dos processos de mudança. A classe trabalhadora - e campesina - precisa construir a sua educação, para que esta sirva aos seus propósitos e objetivos. Importar 
uma educação para a classe trabalhadora limita ou até impossibilita os caminhos e as formas de se forjar processos de mudanças sociais.

Ao se tratar de uma educação do MST, cabe destacar que não se trata de uma educação circunscrita a um movimento social, ou mesmo aos movimentos sociais. Trata, isto sim, de afirmar uma educação vinculada a uma classe que objetiva um horizonte de transformação social; uma educação que abra um leque universal para o conhecimento. Acreditamos que não há um limite para o conhecimento, mas que há posicionamento político; e isto diferencia e dá a tal educação um caráter universal e transformador. Sendo o objetivo do Movimento a transformação social, a educação no MST se volta a este interesse, necessitando de uma densidade cultural, e um alastramento universal do conhecimento, desenvolvendo as várias dimensões do ser humano.

Os processos pedagógicos se elevam numa "perspectiva de ação", não como processos isolados ou até mesmo separados; embora haja a necessidade de compreender teorias com elevado nível de abstração, os processos pedagógicos precisam levar a um objetivo concreto de materialização de uma prática social. Nada é somente teoria, ou somente prática: há uma relação ininterrupta entre ambas.

Dentro do caderno de princípios do MST, está presente a relação que a educação e a escola devem ter com os desafios do seu tempo histórico. A educação para o MST deve estar voltada para a realidade do meio rural, como um instrumento que contribua para solucionar os problemas do campo e garantir uma melhor qualidade de vida. A cooperação seria a chave para construir novas relações no campo, apreendendo a organização e formas de luta pela terra e pela Reforma Agrária. A cooperação possibilitaria, segundo os documentos da educação no MST, uma organização coletiva da produção, abrangendo o trabalho, a comercialização, o acesso às novas tecnologias, enfim, as necessidades básicas e de avanço na qualidade de vida das famílias assentadas.

É compartilhado também o entendimento de que a sociedade está permeada de relações nocivas à humanidade, relações próprias do modo de produção capitalista, que prima pelo indivíduo como supremo e independente, abolindo todas as formas de unidade entre os povos. Entendemos que tais relações subjugam ou mesmo extirpam 
valores essenciais fundantes de qualquer sociedade. A educação e a escola têm, então, como papel fundamental construir relações que se põem em enfrentamento com o atual sistema, relações humanistas, que considerem os povos acima da propriedade de bens, o ser humano acima de qualquer propriedade; relações que põem a propriedade a serviço de toda a humanidade.

A escola pode ser o espaço onde se trabalhem valores que considerem tal perspectiva humanista e socialista, tais como: o sentimento de indignação frente às injustiças e à perda da dignidade humana; o companheirismo e a solidariedade nas relações entre pessoas e coletivos; o respeito ao meio ambiente; o sentimento internacionalista das lutas sociais, dentre outros.

A formação humana precisa ser permanente e incisiva, considerando toda a carga política/ideológica que dominou (e domina) o povo a reagir a qualquer mudança mais radical - uma dominação ideológica viva nas pessoas, não só uma carga ideológica histórica, como elemento do passado, mas presente e projetada ao avanço das relações produtivas capitalistas. Assim, a formação humana se insere num contexto de enfrentamento político e ideológico de classes, interminável no campo das relações subjetivas, superáveis em sua objetividade.

\section{Princípios Pedagógicos}

Os conteúdos trabalhados na escola são ancorados nos princípios de educação como instrumentos necessários para se chegar ao conhecimento, e como instrumentos, precisam ser selecionados de forma que sejam formativos e socialmente úteis. Segundo a proposta de educação do MST, o trabalho tem valor fundamental. Tem o trabalho a capacidade de nos identificar como classe, de gerar novas relações sociais, e é através dele que se produz a riqueza. Vincular trabalho à educação possibilita entender que é através dele que se produzem as riquezas e saberes, e sobre as diferenças entre relações de exploração e relações que possibilitem a construção social pelo trabalho. O trabalho estabelece a relação entre teoria e prática, produzindo conhecimentos sobre a realidade; possibilitaria também a participação dos trabalhadores, bem como favoreceria a formação da consciência de classe. 
Outro princípio de educação no MST é o vínculo orgânico entre processos educativos e processos políticos. Admitiria alimentar a indignação ética diante das situações de injustiças e de indignidades humanas; autorizaria desenvolver atividades e estudar conteúdos voltados à formação política dos estudantes; vincular a vida dos estudantes à luta social do MST e da classe trabalhadora, e incentivar os estudantes a se organizarem e lutar por seus direitos. Segundo este princípio, a meta é que os educandos e educandas cheguem a ser militantes da classe trabalhadora, pertencentes à organização social.

Outro vínculo presente nos princípios é entre processos educativos e processos econômicos. Este tem por fim aproximar os estudantes do funcionamento do mercado e dos processos produtivos, teoricamente bem como na prática, para melhor compreender o funcionamento da sociedade capitalista.

A gestão democrática é outro principio de educação no MST. Aqui se objetiva inserir todos os envolvidos na escola em espaços de tomada de decisões: professores, estudantes e comunidade. Um dos passos para que se possibilite a gestão democrática é a auto-organização dos/das estudantes - processo de criação de um coletivo dos estudantes que possibilitaria espaços de tomadas de decisões e discussões importantes na sua formação. É igualmente importante que haja a criação de coletivos pedagógicos e formação permanente dos educadores, marcando também que só há processo realmente educativo se houver uma coletividade de educadores.

\section{A Escola: um Breve Histórico}

Localizado no município de Passos Maia/SC, o assentamento Zumbi dos Palmares ocupa a área da antiga Fazenda Santo Antônio. As famílias residentes no assentamento são provenientes de várias regiões do estado de Santa Catarina (Vargeão, Passos Maia, Campo Erê, Caçador e Calmon), tendo participado da ocupação histórica da Fazenda Ameixeira, que reuniu cerca de 800 famílias e foi organizada pelo MST. O nome do assentamento homenageia a data de ocupação da área (20 de novembro de 1996), que coincide com o aniversário da morte do lendário líder quilombola Zumbi dos Palmares, 
símbolo de luta e resistência. O decreto de desapropriação da área foi promulgado em 27 de dezembro de 1996, e a emissão de posse em 30 de janeiro de 1997. A criação do Projeto de Assentamento é de 14 de março de 1997.

Logo após a ocupação da área de terra, uma das principais preocupações das famílias Sem Terra foi o acesso à educação para as crianças que ali estavam entendendo que a educação era um direito de todos e um dever do Estado. Assim, a coordenação do acampamento pressionou a prefeitura do município de Passos Maia para garantir a abertura e o funcionamento de uma escola para atender a demanda que ali existia, ou seja, para que todas as crianças das séries iniciais do ensino fundamental tivessem aulas no acampamento. A alternativa encontrada conjuntamente foi a de contratar educadores do acampamento ${ }^{9}$ para lecionarem no próprio local e oferecer transporte para as crianças de $5^{\mathrm{a}}$ a $8^{\mathrm{a}}$ séries estudarem na cidade. A partir das negociações com a administração municipal da época, foi conquistado, então, o direito à educação das crianças acampadas.

Mesmo não habilitados, os educadores foram escolhidos pela coordenação do acampamento considerando o vínculo direto com o MST. A opção respeitou as linhas políticas discutidas dentro da organização do Movimento, que os educadores fossem da própria comunidade. Um dos princípios seguidos é a garantia de qualidade na educação: “Educação de qualidade para todos, umas das lutas do MST!” (Dossiê MST Escola, 2005, p.160). Este princípio foi considerado ao eleger os educadores do próprio acampamento porque "educadoras/educadores que não conhecem a realidade (seja a próxima, seja a distante), não têm como desenvolver um ensino que a tenha como base!”. (Dossiê MST Escola, 2005, p.168). Pertencentes ao acampamento, estariam cientes da realidade local e, através da formação promovida pelo MST (curso de magistério e cursos informais de formação política), também da realidade “distante”. Estes educadores estavam cursando o magistério ou tinham cursado apenas o ensino fundamental. O assentamento Zumbi dos Palmares contava com seis educadores trabalhando diariamente com as crianças nos barracos de lona preta construídos pelas famílias Sem Terra.

\footnotetext{
${ }^{9}$ Primeiro estágio após a ocupação da terra, anterior ao assentamento, momento este em que as famílias possuem o contrato de concessão de uso da terra.
} 
A educação no período de acampamento tinha um caráter que ia para além da escola como instituição. O vínculo direto com o acampamento, o distanciamento do Estado como instituição normativa, as necessidades vividas cotidianamente no fazer escolar traziam elementos próximos a uma educação omnilateral.

Não é possível compreender o sentido da experiência de educação no e do MST, se o foco de nosso olhar permanecer fixo na escola. Somente quando passamos a olhar para o conjunto do Movimento, e com a preocupação de enxergá-lo em sua dinâmica histórica (que inclui a escola), é que conseguimos compreender que educação pode ser mais do que educação, e que escola pode ser mais do que escola ${ }^{10}$, à medida que sejam considerados os vínculos que constituem sua existência nessa realidade. (CALDART, 2004. p.221 - 222).

Ao mesmo tempo em que se distribuíam as famílias nas áreas para o assentamento, a escola ia se dividindo em determinados limites até que ficou aquinhoada em quatro espaços, continuando a ser de chão batido e com condições precárias. Quatro educadores ficaram no Assentamento Zumbi dos Palmares, divididos em duas escolas; uma educadora assumiu o Assentamento 20 de Novembro, com uma escola, e duas educadoras assumiram a escola do Assentamento 29 de Junho.

A partir do ano de 1997, quando as famílias já estavam divididas por áreas, conforme citado acima, o foco da luta pela educação foi a conquista da nucleação em um único espaço físico, permitindo completar o ensino fundamental na escola do assentamento.

Em 1998 foi elaborado o primeiro projeto para a construção de uma escola na região para abrigar todas as crianças da educação infantil até a $8^{a}$ série do ensino fundamental. Essa escola tinha como proposta ser nucleada, mas permaneceria dentro do assentamento, reivindicação das famílias Sem Terra. O objetivo de nuclear as escolas foi facilitar o acesso por estar na região dos assentamentos e, principalmente, para trabalhar a educação de forma omnilateral.

Através da mobilização e da marcha das famílias Sem Terra para a capital catarinense, num enfrentamento direto ao poder estatal, no final de 2002, foi

\footnotetext{
${ }^{10}$ Grifos da autora.
} 
conquistada a liberação do projeto para a construção da escola. Após dois anos (2004) a escola foi inaugurada.

A partir daquele momento houve um maior controle do Estado, representado mais diretamente pelo governo municipal. A contratação de educadores é feita respeitando os processos seletivos (realizados então pela prefeitura e não mais pelo MST), e a estrutura física da escola é mantida pelo município, o que melhorou o nível formacional dos educadores, mas promoveu um distanciamento do assentamento em relação à escola e entre escola e MST. Atualmente a escola referida conta com 13 educadores para o ensino fundamental e mais 17 funcionários, além de um profissional para orientação pedagógica e um diretor ${ }^{11}$.

A história da escola se desdobra em três momentos distintos. A fase de acampamento com uma única escola multisseriada; a distribuição das famílias nas áreas; e a abertura de quatro novas escolas multisseriadas; e, por fim, o assentamento das famílias em lotes individuais e a nucleação das escolas de pré-escolar a $8^{a}$ série do ensino fundamental.

Ao longo de uma trajetória de mais de 15 anos, a construção da Escola Nossa Senhora Aparecida passou por distintos momentos delimitados aqui por nós em três grandes períodos: o período de acampamento; o assentamento das famílias e as escolas multisseriadas e a nucleação da escola em uma comunidade de um assentamento. Em cada um destes períodos estão presentes elementos da educação proposta pelo MST, em diferentes níveis, bem como apresenta elementos de uma educação omnilateral de forma menos perceptível ou impraticável em alguns momentos da história.

De início percebemos que a escola em si é incapaz de proporcionar uma formação omnilateral se apresentada como entidade isolada da vida social, incapaz de ser parte da produção da vida das pessoas. A escola em si, cerrada em suas paredes, tende a não ir além de potencializar uma das dimensões humanas: aquela voltada à força de trabalho (precarizada) para o mercado de trabalho. No percurso da história da escola em questão esta foi a dimensão a prevalecer, embora não a única. Outros momentos revelam

\footnotetext{
${ }^{11}$ Dados de 2012.
} 
gérmens de uma formação mais ampla, uma relação que possibilitou vislumbrar outras dimensões da formação humana.

O período de acampamento foi marcado pela coletividade na luta por objetivos próximos e comuns: a conquista da terra, da moradia, de saúde e educação/escola, entre outros. Esta unidade possibilitou a superação, mesmo que objetiva, do individualismo presente na sociedade capitalista atual. Este objetivo comum levou a uma forma organizativa coletiva destacando a totalidade naquele meio social como nos diz a professora S.A.,

[...] um problema de todos a ser resolvido por todos, no acampamento nós tínhamos unidade, se ocorresse algum problema na escola todos do acampamento ajudavam a resolver, nós discutíamos juntos e dividíamos as tarefas para resolver os problemas. A escola era parte do acampamento como cada família era. (depoimento da professora S.A.).

Esta unidade colocava a escola numa posição de estar junto com o acampamento, compartilhando seus problemas como sendo coletivos e contribuindo para a solução dos problemas das famílias acampadas. Esta vinculação possibilitou uma relação direta da escola com a comunidade, logo com o MST. Vemos aqui os princípios da educação no MST sendo postos em prática no processo da luta pela terra, bem como elementos de uma formação mais ampla dos estudantes.

Percebemos no depoimento da professora R.N.Z. que

[...] no acampamento nós tínhamos o acompanhamento do setor de educação do MST, que passava pra nós materiais sobre os princípios da educação do MST, acompanhava sempre as aulas e nos ajudavam sempre. Assim nós conseguíamos trabalhar na escola os princípios da educação do MST.

Este acompanhamento presente do setor de educação do MST revela um distanciamento, mesmo que tenha sido inicial, do Estado como instituição reguladora da educação. À medida que o controle sobre a escola - e aqui falamos em grade curricular, controle das horas/aula trabalhadas, etc. - era feito pelas famílias acampadas, possibilitava uma forma organizativa com tempos e currículos diferentes. Essa autoorganização e autocontrole proporcionavam trabalhar as várias dimensões do sujeito histórico, como aprender a tomar decisões importantes para a vida, resolver problemas cotidianos da escola e do acampamento; contribuir no geral da produção da vida daquele 
coletivo, bem como participar das lutas promovidas pelo MST ou mesmo pelo acampamento.

Outro fator importante a considerar diz respeito à docência. As educadoras da escola tinham vínculo direto com a ocupação, estavam acampadas com os mesmos objetivos e as mesmas condições que seus educandos. Isso possibilitava ampliar o vínculo entre escola e acampamento; dava margem para um amplo campo de formação para os estudantes, com expressões nos campos da ética, do fazer prático, da criação intelectual, artística, da afetividade, da sensibilidade, da emoção, etc. Possibilitava desenvolver posicionamento crítico frente aos problemas sociais vivenciados por si e por sua classe quando inseridos nas lutas sociais; perceber os problemas sociais e como eles estão arranjados na sociedade, a começar pela luta pela terra; e o direito não garantido de ter escola de qualidade sob a responsabilidade do Estado.

Com a divisão de lotes individuais de terra, a escola passa da mesma forma por uma divisão, não apenas física, mas também política e pedagógica. A produção social da vida varia de forma, logo se demuda a organização política da vida das pessoas agora assentadas. Aquilo que era de interesse comum passa a ser de interesse individual, inclusive a escola. Neste período, o Estado - representado pela secretaria municipal de educação - assume três escolas multisseriadas; há um fracionamento estrutural, político e pedagógico. Político porque cada escola se reveste de um horizonte local; há um fracionamento geográfico da luta quando se regionaliza os problemas estruturais de cada escola não mais vendo o assentamento como parte da escola, apenas as famílias assentadas vendo a escola e seus problemas práticos estruturais, como a falta de salas de aula adequadas e a falta de educadores em algumas situações ${ }^{12}$.

Houve também um distanciamento do setor de educação do MST e da presença dos princípios da educação do MST na escola; embora ainda houvesse acompanhamento, foi reduzido consideravelmente. Os estudantes das séries finais do ensino fundamental não mais tiveram acompanhamento do coletivo, ficando apenas a responsabilidade

\footnotetext{
${ }^{12}$ Quando foram distribuídos os lotes e a escola foi dividida em três, não conseguimos mais trabalhar juntos, trocar ideias, participar das lutas que fazíamos quando no acampamento, nem participar nas assembleias para ajudar a tomar decisões; ficamos distantes e até desmotivadas (depoimento da professora S.A.).
} 
individual de sua família. Ao mudar a forma de produção da vida, muda também a forma e a concepção de educação. A formação humana toma outro rumo.

Um fator importante neste processo foi a permanência de educadores assentados e vinculados diretamente ao assentamento, o que permitia uma qualidade relacional na produção do conhecimento com a realidade social dos estudantes. E as próprias necessidades gritantes das escolas levavam à organização e vinculação entre processos teóricos e práticos como, por exemplo, produção de hortaliças feitas pela comunidade escolar e a participação em atividades de produção das famílias assentadas.

Contudo, com a conquista da nucleação, bandeira de muitas mobilizações, marchas e ocupações, cria-se um "corpo estranho" dentro dos assentamentos. São rompidos os elos entre escola e assentamentos/assentamentos e escola: as famílias assentadas, os educadores, passam a entender que a educação é de responsabilidade do município, tanto no aspecto do financiamento, quanto no processo político e pedagógico; a produção social da vida quase nada mais tem a ver com educação. Essa compreensão se generaliza e isola a escola de seu contexto social.

Vários fatores secundários contribuíram para este isolamento: O currículo escolar passa a ser seguido conforme orientações da secretaria municipal de educação, a qual seguia o currículo nacional; a forma de organização da escola passa a seguir à risca as determinações do poder municipal, o qual passa a assumir também a sua gestão. Com a nucleação do ensino fundamental, o quadro de educadores se torna hegemônico; muitos deles estão desvinculados da realidade dos assentamentos, desconhecendo o contexto em que se constituiu a escola; há por parte dos mesmos um desconhecimento em relação à proposta de educação do MST, tal qual vinha sendo trabalhada, e até mesmo desconhecimento e rejeição quanto à realidade das famílias assentadas e dos estudantes da escola. Nesta configuração, a escola desconsidera o contexto histórico no qual está inserida e se afasta da possibilidade de uma proposta que considere as várias dimensões da formação humana.

Algumas experiências vêm sendo desenvolvidas para ampliar o leque da formação humana na escola, sendo que uma delas é a auto-organização dos educandos. Seu 
objetivo é possibilitar espaços de participação das decisões a serem tomadas na escola, potencializando entre os educando a capacidade de organização, de resolução dos problemas, de vivência da coletividade. Outro elemento é a constituição dos tempos educativos, como o "tempo trabalho" - momento em que os educandos se organizam para realizar tarefas vinculadas à sobrevivência, tais como produção de hortaliças e de mudas no viveiro da escola, limpeza e organização do espaço escolar; o "tempo formatura" - momento em que os educandos são desafiados a coordenar apresentações feitas pelos colegas, cantar o hino nacional e do MST. Embora sejam tentativas de avançar para uma educação omnilateral, a estrutura organizativa da escola, horários e grade curricular não possibilitam mudanças educativas significativas.

\section{Considerações Finais}

A luta por escola é objetivo que caminha junto com a luta pela terra; porém, de imediato, os Sem Terra percebem que lutar por escola é insuficiente e que se faz necessário lutar por educação. Ademais, percebem que para organizar a educação que almejam é preciso uma luta mais ampla, que vai para além das bandeiras da educação. A escola, tanto nos seus aspectos políticos quanto pedagógicos, está determinada pela forma de organização da sociedade capitalista e pelos interesses do grande capital.

Educar pessoas na amplitude da formação humana incorre seguir na contramão dos interesses do capitalismo e de sua estrutura de produção, e que distribuir terras e riqueza torna-se um afronta às demandas do capital. A história da Escola Nossa Senhora Aparecida se enquadra neste contexto das lutas sociais, um espaço em constante disputa de interesses distintos. De um lado, a estrutura estatal representando os interesses da classe dominante, que tem como objetivo formar força de trabalho para as necessidades da produção capitalista; de outro, os movimentos sociais protagonizando a tentativa de construir uma formação mais ampla, crítica dos problemas sociais provocados pela estrutura econômica do sistema atual.

A formação do homem/mulher omnilateral demanda um conjunto de questões que vão para além da escola, mas que não tiram desta instituição a possibilidade de 
contribuir para esta formação. Grosso modo, podemos afirmar que a estrutura em que as escolas estão organizadas - e para que sejam financiadas têm de cumprir com esta organização -, engessa as possibilidades de ampliar o campo da formação humana. Um exemplo disso é o caso da escola objeto deste estudo. No período de acampamento não havia recursos materiais por parte das políticas públicas estatais, as condições eram precárias, mas a estrutura organizativa da escola se pautava segundo as demandas do acampamento; sua organização e gestão eram feitas livres do engessamento estatal. Consideramos este um elemento importante para entender um dos limites de uma educação onilateral nas escolas, embora não seja o único.

Uma formação omnilateral em sua totalidade somente será possível em outro modo de produção que não o capitalista. Não vivemos em uma ilha onde podemos nos isolar das influências do sistema capitalista. Porém, podemos desenvolver experiências semelhantes nos moldes da Escola Nossa Senhora Aparecida, que ao longo de 15 anos permitiu que concebêssemos alternativas possíveis no sentido de avançarmos rumo a uma formação humana omnilateral.

\section{Referências}

ARROYO. M. G., CALDART. R. S., MOLINA. M. C. (orgs). Por uma educação do campo. Petrópolis, RJ: Vozes, 2004.

AUED. B. W., VENDRAMINI. C. R. (Orgs). Educação do campo: desafios teóricos e práticos. Florianópolis: Insular, 2009.

CALDART, Roseli Salete. Pedagogia do Movimento Sem Terra. 3. Ed. - São Paulo: Expressão Popular, 2004.

ENGELS, Friederich. O Papel do Trabalho na Transformação do Macaco em Homem. Neue Zeit, 1896. Edição soviética de 1952, de acordo com o manuscrito, em alemão. Disponível em: http://www.marxists.org/portugues/marx/1876/mes/macaco.htm, acesso no dia 12 de agosto de 2011, 23:15h. 
FREIRE, Paulo. Pedagogia da Autonomia: saberes necessários à prática educativa. 27 ed. São Paulo: Paz e Terra, 1996 (Coleção Leitura)

HOBSBAWN, Eric J. Sobre história. São Paulo: companhia das Letras, 1998.

ITERRA - Instituto Técnico de Capacitação e Pesquisa da Reforma Agrária. Dossiê MST Escola: documentos e estudos 1990 - 2001. Caderno de educação $n^{\circ} 13$ - edição especial. $1^{\text {a }}$ ed., agosto de 2005.

MARX, Karl. FRIDRICH, Engels. A ideologia alemã. São Paulo: Centauro, 2002.

. Escritos de juventud. In: MARX e ENGELS Obras fundamentales. $1^{\mathrm{a}}$.

Reimpresión. México - DF: Fondo de Cultura Econômica, 1987, vol. 1.

. Crítica ao Programa de Gotha. In. Obras Escolhidas em três tomos. Tradução: José BARATA-MOURA. Editorial "Avante!" 1982.

. Para a Crítica da Economia Política. In. Obras Escolhidas em três tomos.

Tradução: José Barata Moura. Editorial "Avante!" 1982. Disponível em:

http://www.marxists.org/portugues/marx/1859/01/prefacio.htm, Acesso em 10 nov. 2011.

. O 18 Brumário e Cartas à Kugelmann, $7^{\text {a }}$ ed., Rio de Janeiro: Paz e Terra, 1997.

MÉSZÁROS, István. A Educação para Além do Capital. Tradução de Isa Tavares. São Paulo: Boitempo, 2005.

MOISSAWA, Mitsue. A história da luta pela terra e o MST. São Paulo: Expressão Popular, 2001.

MUNARIM, Antonio; BELTRAME, Sônia; CONDE, Soraya Franzoni; PEIXER, Zilma Izabel. (Orgs.). Educação do Campo: reflexões e perspectivas. Florianópolis: Insular, 2010.

ORSO, Paulino José; GONÇALVES. Sebastião Rodrigues, MATTOS. Valci Maria (Orgs.). São Paulo: Expressão Popular, 2008.

PISTRAK, Moisey Mikhaylovich. A Comuna Escolar; tradução de Luiz Carlos Freitas e Alexandra Marenich. São Paulo: Expressão Popular, 2009. 
SÁNCHEZ VÁZQUEZ, Adolfo. Filosofia da práxis. Buenos Aires: consejo Latinoamericano de Ciencias Sociales - CLACSO; São Paulo: Expressão Popular, Brasil, 2007. 